\title{
REMAINING MANAGEMENT FOR AUTOMATIC SHEET-METAL CUTTING
}

CONFERENCE PAPER $\cdot$ NOVEMBER 1995

DOI: 10.1109/ETFA.1995.496660 · Source: IEEE Xplore

DOWNLOADS

11

3 AUTHORS, INCLUDING:

\section{Eduardo Cuesta}

University of Oviedo

69 PUBLICATIONS 116 CITATIONS

SEE PROFILE
VIEWS

51
Carlos Rico

University of Oviedo

29 PUBLICATIONS 43 CITATIONS

SEE PROFILE 


\section{TITLE: REMAINING MANAGEMENT FOR AUTOMATIC SHEET-METAL CUTTING}

\section{Authors:}

Eduardo Cuesta González, Daniel Ceán-Bermúdez Pérez, José Carlos Rico Fernández Dept. of Manufacturing Engineering. University of Oviedo, Campus of Gijon ecuesta@uniovi.es

\section{ABSTRACT:}

The Manufacturing Processes Area of the Technical School of Industrial Engineers in Gijón is been developing since the last two years, a CAD/CAM system for automatic sheet-metal cutting processes (Oxygen-cut, plasma arc, laser or waterjet), including several modules in relation with geometry preparation, cutting toollaths generation and edition, special developable surfaces for cutting process, etc.

In this communication, we are going to describe a new module which deals with the metal remains.

The remaining management module allows to define and improve the metal remnants made by sheet cutting operations (called remains). In order to make quite sure its computer loading and its better improvement (re-utilize it again), these remains are translated into text-files which contains not only its geometry definition but also all its technological parameters as material, thickness, original (base) sheet, original cutting program, etc.

To the remains list introduced in the system, we can automatically add new remains with the same original stock sheet parameters (were its come from). The remains defined could be rectangular, circular or any polygonal shape. Also it could be edit and delete. The edition regenerates the remains geometry above the piece/s to cut and allows the user to test if it's useful or not. The remaining management allows searching the best remains which are useful to cut some pieces again by material, thickness and size requirements.

\section{KEYWORDS:}

CAD/CAM, sheet cutting processes, management, remains (metal remnants)

\section{SUBMISSION AREA:}

Manufacturing Integrated Systems. 


\section{1.- INTRODUCTION}

Nowadays, the difference between the application of the new technologies in the sheet cutting and forming processes and the traditional machining processes is considerable reduced. In spite of this, if we want introduce the new technologies in the cutting companies we need to employ NC machines and even CAD/CAM systems for design, edit and program cutting toolpaths, including the final communication from the computer to the NC machine.

The present application, deals with these problems and with other features in relation to automatic sheet cutting processes. The program is developed under the AutoLISP graphic programming language by AutoCAD (release 12). It was done in association with a company specialized in metal cutting and it belongs to a research project which is founded by the "Fundación para el Fomento en Asturias de la Investigación Científica Aplicada y la Tecnología" (FICYT).

The application is perfectly integrated on the AutoCAD program. the AutoCAD commands and menus never change and the user-interface uses the same pop-us menus and dialogue windows. Besides it allows the user to employ the whole drawing potential.

We always tried to make a modular application. Each particular problem about sheet cutting process is solved by automatic functions in the specific module:

- Design and geometry preparation.

- Sheet development module.

- Remains (remnant) management module.

- Automatic toolpaths generation.

- Toolpaths edition.

- Toolpaths Simulation (analyze kerf simulation) module.

- Post-process.

In this report, we are going to describe the Remaining management module.

\section{2.- REMAINING MANAGEMENT MODULE}

During the sheet cutting process, a lot of remnants and remains (like metal clippings) have been produced. When the amount of these metal remains are considerable, it seems logical to think about how we can improve it again.

Having in mind this idea, we have developed, into the base-program, a module which deals with the remaining management. We have to join the use of this module with a physical remaining management (for instead, in a sheet-metal store). It is no worth having one management program if we didn't order, store and codify the material before.

The management module allows to define the remains like remaining material originating from a particular cutting operation, it also allows to search the best remain/s which could be use again in the cut of other new pieces.

The remains defined through the management module turn into ASCIl files with "*.REC" extension and are placed in an independent directory of the management module. In this way, 
the previous definite remains can be used in the base-cutting program without having to employ the management module.

These remains contain the whole information needed to its right definition (material, size, etc.) and can be incorporated as new original sheet at the beginning of the cutting process, in the same way to standard sheets

\section{1.- New remains definition}

The definition of a new remains usually carries out after a cutting process. So that, the systems knows the name of the cutting-program (the user introduces that name at the beginning of the process), the initial size of the employed sheet, its material, thickness and density. Therefore, if we finally wish to define a remnant with the remaining material, the systems previously knows all these data and they are automatically loaded in its own remains database (remains stock).

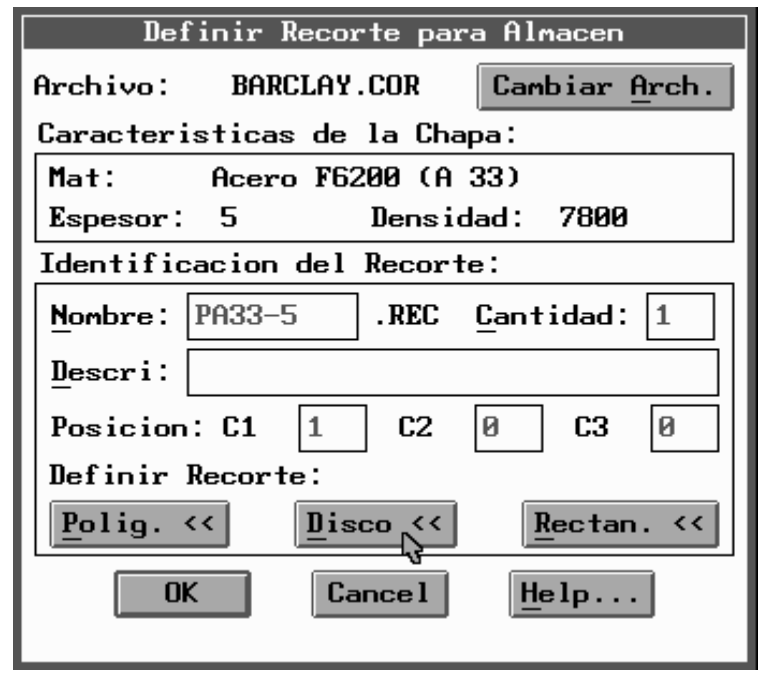

Additionally, the user has to introduce the following data:

- The name of the remain (it will be used by the program internally in order to generate the filename "*.REC", where all associated information will be loaded)

- Description (reference free field or company codification)

- Amount (number of identical remains). It can be useful when we makes mass cutting production and we obtain a lot of identical remains.

- Storage position. The system uses three free fields (C1, C2 and C3) to identify its position in a hypothetical store. For instead, $\mathrm{C} 1=\mathrm{X}$ position, $\mathrm{C} 2=\mathrm{Y}$ position and the filed $\mathrm{C} 3=\mathrm{Z}$ position.

Finally, in order to obtain the right definition, we have to introduce the geometric shape and the size of the new remains. Previously, the system allows selecting three basic geometric shapes: polygonal, rectangular and disk shape (fig.1).

If the Polygonal shape is selected, the user has to draw on the screen the polygonal profile, marking the vertex like the polyline drawing mode. On the other hand, and with the purpose of getting an automatic and quick remains searching, we have to define an interior rectangle (the biggest we can) and the exterior rectangle (the smallest enclosing we can). 


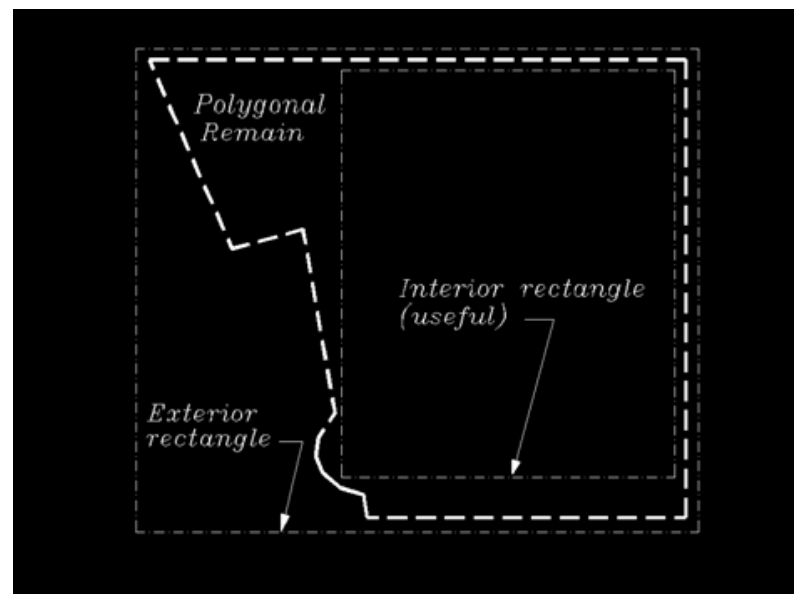

With the information of these two rectangles, the program calculate the "profitable ratio", percentage which means how similar is the real remain shape compared to the rectangular shape, considering as base the $100 \%$ value for this ratio in the case of exactly rectangular remains, and $50 \%$ value for disk shapes (the relation between the interior and exterior squares in a circle). If the profitable ratio is reduced and the user consider that he can obtain other interior and exterior rectangles with better ratio, the program allows their redefinition.

If the Rectangular shape is chosen, the system allows to generate a remain with this shape, and with any orientation in the plane. The "profitable ratio" for next searchings' is automatically fixed to $100 \%$. Therefore, the definition of the exterior/interior rectangles is not needed.

In the case of selecting a disk shape, we only have to introduce a center point and other point for the radius. This remain shape is useful when there are big interior profitable holes in the pieces we are going to cut (fig.3).

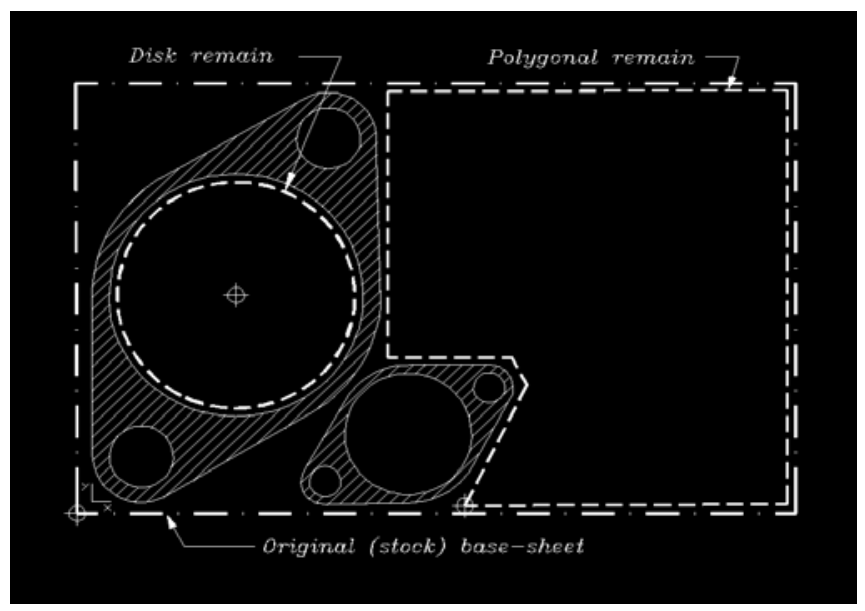

With this information, the new "remain entity" is rightly defined taking part of the internal remains list in the program.

\section{2.- Remains searching}


When a cutting process starts, not only the pieces/s profiles are required, but also the kind (material, thickness) and size of the sheet. In this sense, the program allows the user to select a rectangular profile with the suitable dimensions. In the same way, the user can use as basesheet one of the loaded remains on the memory. The "search" option in the management module achieves to choose the best remain/s automatically selecting the following parameters:

- Material: the user has to select one material from the material list included in the baseprogram.

\section{- Thickness}

- Geometry: The remaining management module has to know the shape of the piece we want to cut in order to fix the minimum size of the required remain. This information can be introduced by screen selection or by typing one rectangle which contains the piece or pieces to cut. If we want a circular (disk) remain we introduce the minimum radius needed.

Once these parameters are introduce, the system search for the suitable remains. Then the screen shows three lists (fig.4):

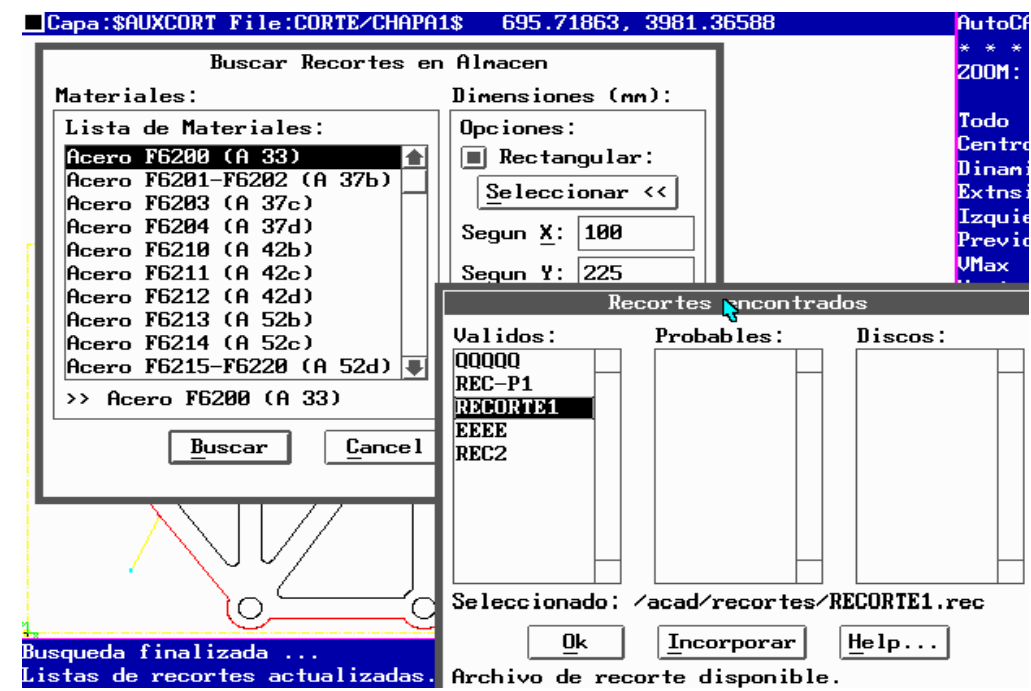

1a- Suitable remains list: Are those remains which have all the desired requirements. In other words, its useful defined rectangles are bigger than the rectangle that we had used to define the piece/s.

2a- Probably remains list: Are those remains without having a useful rectangular area; however they have an exterior area which includes our piece. Usually, here there are the polygonal remains with a low "profitable ratio" (<=50\%). If we select a probably remain, is useful to use the "look" option, which allows to see the real remain above the profile/s to cut. This option also allows the movement and rotation in order to test its validity.

3a-- Suitable disk list: Are those suitable remains with circle shape.

In those three list, the material and thickness are the same that the "remains ordered". 
Selecting one remain from any of the list, there is an option which allow to change the current sheet for the selected remain.

\section{3.- Remain list}

The meaning of the remain list is to see all the associated parameters from the selected remain of the list (fig.5):

\begin{tabular}{|c|}
\hline Listado de Recorte \\
\hline $\begin{array}{l}\text { Pro. Origen: C: } \backslash A C A D \backslash C O R T E \backslash B A R C L A Y . C O R \\
\text { Dib. Origen: /acad/corte/barclay\$.dwg } \\
\text { Caracteristicas de la Chapa: }\end{array}$ \\
\hline $\begin{array}{l}\text { Mat: } \quad \text { Acero F6200 (A 33) } \\
\text { Espesor: } 5\end{array}$ \\
\hline Identificacion del Recorte: \\
\hline $\begin{array}{l}\text { Nombre: pa33-5x } \quad \text { Cantidad: } 1 \\
\text { Des: } \\
\text { Posicion: } 1 \text { - } 0 \text { - } 0 \\
\text { Tipo de Recorte: } \quad \text { poligonal } \\
\text { Parametros de busqueda: } \\
\text { factor de aprovechamiento: } 41.29 \% \\
\text { Rectang. Util: 2483.295 x } 845.9908 \\
\text { Rec. Exterior: } 3104.638 \times 1638.808 \\
\text { Centro: 0.0000, } 0.0000 \text { Radio: } 0.0000\end{array}$ \\
\hline Help... \\
\hline
\end{tabular}

- Original cutting program where the remain come from.

- Original cut drawing where the remain come from.

- Original stock sheet data. (material, thickness, density).

- Identification remain data:

. Name (without *.REC extension)

. Description or Reference (if it has)

. Kind (rectangle, polygon or disk)

- Remain searching parameters:

. Profitable ratio (\%)

. Dimension of the interior (useful) rectangle: minimum $X, Y$

. Dimension of the exterior rectangle (smallest enclosing rectangle): maximum $X, Y$.

. Center and radius (if it is "disk").

\section{4.- Remains deletion}

Any remain can be deleted in the program database. This operation can be realized using a particular option defined in the remaining management module or through the computer operation system (Windows or DOS).

\section{3.- REFERENCES}

[1]- Ayala, A. Técnica y Práctica de Calderería. Edit. Urmo, 1987. 
[2]- Ceán-Bermúdez, D.; Cuesta, et al. Desarrollo bajo AutoCAD para el corte automático de chapa. XI Congreso Nacional de Ingeniería Mecánica. Valencia (España), Noviembre 1994.

[3]- Cuesta, E.; Rico, J.C. et al. Aplicación de los sistemas CAD/CAM al corte de chapa. International Congress of Projects Engineering. Asturias (España), Octubre 1994.

[4]- Lobjois, Ch. Tecnología de la Calderería. Edit. CEAC, 1990.

[5]- Rico, J.C.; Cuesta, E. et al. Funciones automáticas para el corte de chapa. Revista IMHE, no 192. pág. 33-35. 1993.

[6]- Rico, J.C.; Cuesta E. et al. Automatic functions for sheet-metal cutting using CAD/CAM systems. 5th International DAAAM Symposium. Maribor (Slovenia), October 1994.

[7]- Sanz, J.M.; Prádanos del Pico, R. Domínguez, M. Bases para la automatización del trazado y corte en las construcciones metálica de calderería. V Congreso Internacional de Expresión Gráfica "Diseño Industrial". Tomo 1, pág. 103-116. Gijón, 1993.

[8]- Tajadura, J.A; López, J. AutoLISP v.12. Edit. Mc. Graw Hill, 1993. 